\title{
Treatment of MIS-C in Children and Adolescents
}

\author{
Sanaa Mahmoud ${ }^{1,2}$ (D) Mostafa El-Kalliny ${ }^{3,4} \cdot$ Alyaa Kotby $^{5} \cdot$ Mona El-Ganzoury $^{5} \cdot$ Eman Fouda $^{6} \cdot$ Hanan Ibrahim $^{7}$
}

Accepted: 8 December 2021 / Published online: 8 January 2022

(c) The Author(s) 2022

\begin{abstract}
Purpose of Review Different treatment approaches have been described for the management of COVID-19-related multisystem inflammatory syndrome in children (MIS-C), the pathogenesis of which has not yet been fully elucidated. Here, we comprehensively review and summarize the recommendations and management strategies that have been published to date. Recent Findings MIS-C patients are treated with different regimens, mostly revolving around the use of immunomodulatory medications, including IVIG and glucocorticoids as first-tier therapy. Refractoriness to IVIG and glucocorticoids warrants a step-up of immunomodulatory therapy to biologic agents such as anakinra, tocilizumab, and infliximab.

Summary We review the current evidence regarding the use of monotherapy versus combination therapy, as well as the current recommendations for assessing thrombotic risk and administering antiplatelet and anticoagulant therapy. We anticipate that future studies will provide evidence for management plans that maximize short- and long-term outcomes.
\end{abstract}

Keywords Multisystem inflammatory syndrome in children · MIS-C · Therapy · Intravenous immunoglobulin (IVIG) · Corticosteroids · Thromboprophylaxis

\section{Introduction}

Evolving evidence and rapidly expanding information are reshaping our understanding of the novel multisystem inflammatory syndrome in children (MIS-C), defined by the $\mathrm{CDC}$ and the WHO on the basis of fever, laboratory markers of inflammation, multisystem $(\geq 2)$ organ involvement, and

Sanaa Mahmoud

smahmoudcairo@gmail.com

1 Division of Allergy and Immunology, Department of Pediatrics, Ain Shams University, Cairo, Egypt

2 University of Pikeville, Kentucky College of Osteopathic Medicine, Pikeville, KY 41501, USA

3 Department of Molecular, Cellular, and Developmental Biology, University of Colorado Boulder, Boulder, CO 80309, USA

4 Medical Scientist Training Program, University of Colorado Anschutz Medical School, Aurora, CO 80045, USA

5 Division of Cardiology, Department of Pediatrics, Ain Shams University, Cairo, Egypt

6 Division of Pulmonology, Department of Pediatrics, Ain Shams University, Cairo, Egypt

7 Division of Critical Care, Department of Pediatrics, Ain Shams University, Cairo, Egypt temporal relationship to severe acute respiratory syndrome coronavirus 2 (SARS-COV-2) (WHO, CDC).

Although MIS-C can be severe, it is relatively uncommon, with an estimated incidence of 2 per 100,000 individuals less than 21 years old [1]. To date, in the absence of randomized controlled clinical trials, there remains a paucity of high-quality evidence for management, resulting in variability across clinical practice worldwide. However, guidelines for the management of patients with Kawasaki disease (KD) and similar conditions, in addition to consensus guidelines based on available literature from observational studies, have helped in the development of the clinical approach for the management of MIS-C. Fortunately, a vast majority of reported patients recover quickly in spite of variations in management.

Current practices and published guidelines for the treatment of MIS-C support the use of intravenous immunoglobulin (IVIG) and/or high-dose corticosteroids as a firstline cornerstone of therapy $[1,2,3 \bullet, 4-8]$. In addition to antithrombotic therapy and second-line treatment with different immunomodulatory drugs (e.g., tumor necrosis factor inhibitor, interleukin-1 inhibitor, or interleukin-6 inhibitor), other supportive therapeutic agents are concomitantly used $[9,10]$. 
Clinical decision-making and treatment plans should be modified as new evidence emerges, especially in patients with comorbid conditions. Treatment should be individualized, based on both multidisciplinary consensus approach and expert opinion $[2,3 \bullet]$.

\section{Methods}

A literature search through principal medical databases was carried out, including from PubMed/Medline, OVID, Scopus, Google Scholar, briefings/reports from the World Health Organization (WHO), Centers of Disease Control (CDC), and guidance provided by the Royal College of Paediatrics and Child Health (RCPCH). We used a combination of the keywords "MIS-C," "Multisystem Inflammatory Syndrome," "Therapy," "IVIG," "Immunomodulators," "Corticosteroids," and "Thromboprophylaxis" to retrieve articles published from inception to August 31, 2021. We included all articles which provided sound data or recommendations and were relevant to our objectives. Two independent authors screened articles and comprehensively reviewed and extracted appropriate data. This article does not contain any studies with human or animal subjects performed by any of the authors.

\section{Overview and Initial Management}

All children meeting the CDC case definition criteria for MIS-C should be monitored in the hospital with possible admission to the PICU and early involvement of a multidisciplinary team. Children meeting the criteria but not requiring hospitalization (e.g. mildly ill with stable vital signs and unremarkable organ dysfunction) should not be considered as MIS-C but should undergo careful outpatient diagnostic evaluation with close clinical and laboratory follow-up, given the risk of progression to a MIS-C diagnosis, especially as inflammatory markers can take time to rise. Supportive care is based on the severity of symptoms. Those presenting with cardiorespiratory compromise or shock often require careful fluid resuscitation, inotropic support, non-invasive, or invasive mechanical ventilation, in addition to standard PICU care [11]. Some children present with vasodilatory shock, which may be refractory to fluid repletion and require vasopressor support, with epinephrine, norepinephrine, or dopamine. If there are signs of tissue hypoperfusion and cardiac dysfunction despite high doses of catecholamines, inotropes such as dobutamine, levosimendan, or milrinone should be considered, although one study commented on avoiding milrinone due to concern of peripheral vasodilation [12]. Pending blood culture results, empirical use of broad-spectrum antibiotics, as indicated by institutional guidelines for sepsis, is recommended for
MIS-C patients who present with signs of shock. Antimicrobial therapy should be refined or de-escalated on the basis of clinical course and microbiological findings. Intravenous immunoglobulin (IVIG), glucocorticoids, and biologic agents constitute the main therapeutic modalities, with different combinations depending on the treatment center (Fig. 1) [13•, 14]. The ultimate aims of management are to decrease systemic inflammation and restore organ function, with the goal of preventing long-term sequelae such as persistent cardiac dysfunction [15].

\section{Immunomodulatory Management}

Although the exact pathogenesis of MIS-C remains elusive, virus-induced post-infective immune dysregulation appears to play a predominant role, with MIS-C commonly developing 2-6 weeks after infection [16]. Proposed immunologic mechanisms include but are not limited to superantigen-like activation of the immune system, and autoantibody production resulting in activation of Fcy receptors on neutrophils and macrophages, causing secretion of pro-inflammatory cytokines [17-19]. Accordingly, immunomodulation is a cornerstone of treatment, with consensus guidelines recommending a stepwise progression of immunomodulatory therapies starting with the first-tier therapy, IVIG, which can sometimes be used as needed before full diagnostic evaluation is completed. Glucocorticoids are used in low doses as adjunctive therapy in patients with the moderate-to-severe disease or in high doses as intensification therapy in patients with refractory disease. Biologics such as anakinra, tocilizumab, or infliximab have been used as adjunct therapy with success by multiple centers; however, based on the latest recommendations of the American College of Rheumatology (ACR) and others, they are used in cases refractory to first-line treatments $[3 \bullet, 20]$.

\section{Intravenous Immunoglobulin (IVIG)}

The adoption of IVIG as a treatment in MIS-C was based on the similarities that MIS-C shares with Kawasaki disease, including coronary artery aneurysms (reported in 9-24\% of MIS-C patients) and findings of myocarditis in many patients $[9,21,22]$. The mechanism of action of IVIG includes inhibition of complement deposition, enhancement of regulatory $\mathrm{T}$ cells, and accelerated clearance of autoantibodies [23]. Although there have been no randomized studies of the efficacy of IVIG, reviews and observational studies have reported efficacious outcomes with an increasing frequency of IVIG use over time [24, 25]. Multiple later studies have reported a frequency of IVIG use greater than $90 \%$, with as little as $0 \%$ mortality $[26,27]$.

Consensus guidelines support the use of high-dose IVIG for all hospitalized patients, administered in a single dose 
Fig. 1 Suggested algorithm for management of MIS-C patients. *VTE risks: obesity, immobilization, age $>12$ years, central venous line, asparaginase, malignancy, soft tissue infection, thrombosis in family. Abbreviations: IVIG, intravenous immunoglobulin; ULM, upper limit normal; TEG MA, thromboelastography maximal amplitude; ECG, electrocardiography; VTE, venous thromboembolism; LV, left ventricular; $\mathrm{EF}$, ejection fraction

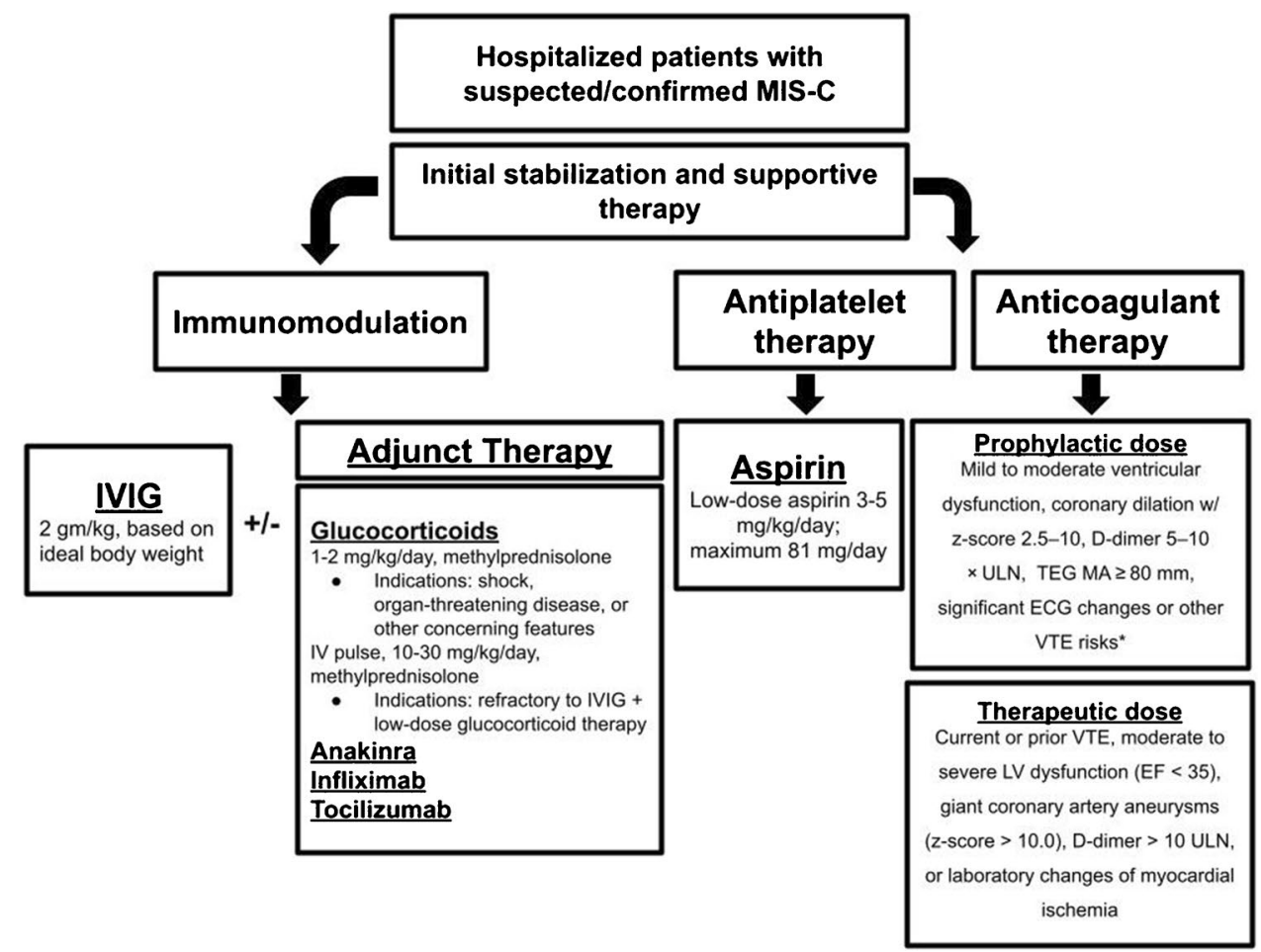

at $2 \mathrm{gm} / \mathrm{kg}$ based on ideal body weight (max $100 \mathrm{gm})[3 \bullet$, 28 ]. Cardiac function and fluid status should be assessed before IVIG administration; patients with depressed cardiac function or vasodilatory/distributive shock should be closely monitored and the use of diuretics should be considered [ $3 \bullet$, 25]. In some patients with ventricular dysfunction, IVIG dose can be given through slower infusion or divided into $1 \mathrm{gm} / \mathrm{kg}$ daily over 2 days, to avoid fluid overload or further cardiac decompensation $[3 \bullet, 25]$. A second dose of IVIG is considered in some recommendations [28•], although, in version 2 of the ACR recommendations, a second dose of IVIG is not recommended for all patients, given the risk of volume overload, hemolytic anemia, aseptic meningitis, neutropenia, and other side effects $[3 \bullet]$.

\section{Corticosteroids}

Corticosteroids are one of the few validated therapeutics in critically ill adult patients with COVID-19 [29, 30]. The rationale for using steroids are their anti-inflammatory properties and frequent use in Kawasaki disease and other inflammatory disorders [31]. A variety of observational studies suggest that corticosteroids are beneficial in MIS-C patients, possibly due to their effect in treating features of cytokine storm and the frequent finding of a shock-like presentation $[14,22]$.

Two recent studies examined the effectiveness of IVIG monotherapy in comparison to combination therapy with IVIG and glucocorticoids in adult COVID-19. In a study by
The Overcoming Covid Consortium, which analyzed data from a cohort of 596 patients, combination therapy was associated with a lower risk of cardiovascular dysfunction and less use of adjunctive immunomodulatory treatments later on, in contrast to IVIG monotherapy [22]. These findings are in line with previous studies suggestive of similarly improved outcomes with combination therapy [14, 32•]. In contrast, a study from the international Best Available Treatment Study (BATS) consortium analyzed data from a cohort of 651 patients and compared three treatment groups: IVIG alone, a combination of IVIG and glucocorticoids, or glucocorticoids alone. There were no statistically significant differences in primary outcomes of mechanical ventilation, inotropic support, death, or reduction in disease severity [33]. However, in patients who received IVIG plus glucocorticoids, there was a significantly decreased risk of escalation of immunomodulatory treatment, compared to patients who received IVIG alone. The length of hospital stay and time until improvement in inflammatory markers was similar across all three treatments. Importantly, neither of these studies definitively answer the question about the most effective single or combination treatment, and neither of these studies addressed the treatment of MIS-C [34].

The American College of Rheumatology (ACR) consensus guidelines for MIS-C suggest that intravenous low-tomoderate dose corticosteroids (methylprednisolone 1-2 mg/ $\mathrm{kg} /$ day, typically in two doses) should be used alongside IVIG in patients demonstrating shock or organ-threatening disease (Fig. 1) [3•]. Methylprednisolone is most commonly 
used and demonstrated better results than dexamethasone in treating hospitalized hypoxic adult COVID-19 patients [35], but other steroids that can be used are dexamethasone $(0.15-0.4 \mathrm{mg} / \mathrm{kg} /$ day, p.o. or IV) and prednisone (1-2 mg/ $\mathrm{kg} /$ day, p.o.) $[22,36]$. This low-to-moderate dose of glucocorticoids may also be considered for administration alongside IVIG in patients who have not yet developed shock or severe end-organ involvement but present with concerning features such as ill appearance, highly elevated BNP levels, or unexplained tachycardia $[3 \bullet, 28 \bullet]$. In patients refractory to initial treatment with IVIG and low-to-moderate dose corticosteroids, corticosteroid treatment can be intensified to pulse doses of methylprednisolone (10-30 mg/kg/day). Refractory disease is defined as persistent fever and/or ongoing significant end-organ involvement.

Children with MIS-C may require a prolonged course of treatment for several weeks to avoid rebound inflammation. Glucocorticoid-related complications are predominantly hypertension and hyperglycemia, with one study reporting an incidence of $4 \%$ in patients who received glucocorticoids in any combination [33]. Upon resolution of fever and clinical improvement, treatment can be transitioned to an equivalent oral dose of prednisolone or prednisone [3•]. Gastrointestinal prophylaxis should be administered during corticosteroid treatment according to institutional guidelines [13•]. All patients should be slowly weaned from treatment depending on the clinical course and the results of serial

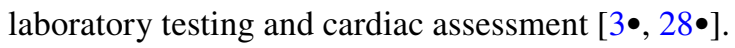

\section{Anti-cytokine Therapy}

Anti-cytokine agents are often successfully used as an initial adjunct therapy to IVIG. However, data evaluating the efficacy of using targeted biologic agents is not yet available $[34,37]$, and later recommendations emphasize the use of biologics primarily for cases refractory to treatment with IVIG and corticosteroids [3•, 20, 28•].

Immunomodulatory treatment with biologic agents includes interleukin-1 (IL-1) blockade with anakinra, interleukin-6 (IL-6) blockade with tocilizumab, and/or monoclonal antibodies to tumor necrosis factor (TNF) with infliximab. There have been no studies supporting routine serial cytokine level assessment in the guidance of cytokine-targeted therapy (CTT) [28•].

\section{Anakinra}

IL-1 is an important effector cytokine of innate immunity that is produced by alveolar type II cells upon infection with SARS-CoV [38, 39]. Anakinra is a recombinant human IL-1 receptor antagonist (IL-1ra) used for rheumatoid arthritis and other inflammatory conditions, including neonatal-onset multisystem inflammatory disease (NOMID) [40]. Studies of anakinra in adult COVID-19 patients have demonstrated improvements in respiratory function and inflammatory markers as well as mortality and the need for invasive mechanical ventilation [41-45].

Anakinra should primarily be considered in MIS-C patients with disease refractory to IVIG and/or corticosteroids, or in patients with contraindications to steroids, especially in cases of MIS-C with features of macrophage activation syndrome [3•]. However, initiation of anakinra as an adjunct therapy to IVIG or before invasive mechanical ventilation may be beneficial [3•]. Schlapbach and colleagues suggest starting dosing at $2-3 \mathrm{mg} / \mathrm{kg} \mathrm{q} 12 \mathrm{~h} \mathrm{s.c.} \mathrm{(total}$ of $4-6 \mathrm{mg} / \mathrm{kg} / \mathrm{day}$, max. $100 \mathrm{mg} / \mathrm{dose}$ ) [28•]. Liver function in patients who receive anakinra should be monitored, due to the risk of increased serum transaminases and hepatitis [46]. However, its short half-life (4-6 h) and quick onset of action allow for frequent reassessment and rapid discontinuation if adverse reactions are observed [28•,47]. Other side effects include neutropenia, leukopenia, thrombocytopenia, headache, abdominal pain, nausea/vomiting, and diarrhea.

In the case of no clinical or biochemical improvement to anakinra treatment within $24-48 \mathrm{~h}$, other targeted immunomodulators such as tocilizumab or infliximab can be considered [28•]. In the case of clinical improvement, anakinra can be discontinued after $48-72 \mathrm{~h}$ with or without tapering, according to institutional practice.

\section{Tocilizumab}

Tocilizumab is a humanized anti-human IL-6 receptor antibody that is used in juvenile idiopathic arthritis and other inflammatory conditions. Initially, tocilizumab appeared to be an effective option for treating adult COVID-19 [48, 49]; however, randomized, double-blind, placebo-controlled trials showed no clear benefit of tocilizumab in preventing intubation or death in hospitalized adult patients with COVID-19 [50, 51]. In addition, safety concerns include an increased risk for infections, and a long half-life (150 h) [28•].

For these reasons, tocilizumab is not recommended for the majority of MIS-C patients; however, it can be considered for use in children with the life-threatening disease in whom prior therapy, including anakinra, has not been effective [3•, 28•]. Given the long half-life, it is usually administered as a single IV dose ( $<30 \mathrm{~kg}: 12 \mathrm{mg} / \mathrm{kg} \mathrm{IV;} \geq 30 \mathrm{~kg}$ : $8 \mathrm{mg} / \mathrm{kg} \mathrm{IV}$; max.: $800 \mathrm{mg}$ ).

\section{Infliximab}

Levels of tumor necrosis factor-alpha (TNF $\alpha$ ), a pro-inflammatory cytokine, have been demonstrated to be associated with severe KD complications and to differ between patients with MIS-C and patients with severe COVID-19 [9, 52]. 
Some studies utilizing infliximab, the monoclonal anti-TNF $\alpha$ antibody, have reported efficacy in the treatment of MIS-C [53]. However, currently, infliximab is not recommended for use in a majority of patients and can be considered on a case-by-case basis in patients who have failed to respond to prior treatments or in patients who present with comorbid conditions such as Crohn's disease [3•, 54].

\section{Thromboprophylaxis and Thrombosis}

\section{Thromboembolism in MIS-C}

Treatment strategy for thromboprophylaxis in MIS-C patients presents multiple challenges since pediatric VTE pathophysiology and risk factor definitions differ from those of adults [55]. MIS-C coagulopathy, in particular, is thought to arise from marked host inflammatory response, cytokinemediated endotheliopathy, and platelet activation [56, 57•]. Multicenter studies have shown an incidence of MIS-C associated thromboembolic events (e.g., pulmonary embolism (PE), deep venous thrombosis (DVT), thrombotic microangiopathy (TMA), and arterial thrombosis including stroke) ranging from 6.5 to $8 \%$, with one multicenter study showing a mortality rate of $28 \%$ in those who developed thrombosis [7, 58-60]. However, the reported incidence likely underestimates the true baseline risk of thrombosis, considering that many patients in these studies received thromboprophylaxis during hospitalization [60]. The recent approaches of Sharathkumar et al. and Bansal et al. together provide comprehensive practical guidance for addressing thrombosis and thromboprophylaxis risk assessment as well as management in most MIS-C cases [57•, 61•].

\section{Thromboembolism Risk}

The first step in deciding on the proper use of antithrombotic therapy resides in the assessment of condition severity, VTE risk factors, location of the patient (outpatient, regular ward, or PICU), and oxygen requirement [57•, 60, 62, 63]. Detailed risk factors of VTE in hospitalized children with COVID-19 are outlined by Goldenberg and colleagues [64]. All management plans consider evaluating all or most of the characteristic coagulation profile, including D-Dimer (usually assessed every 24-72 h), PT/INR, PTT, fibrinogen, platelet count, lactate dehydrogenase (LDH), thromboelastography with platelet mapping (TEG with PM), or rotational thromboelastometry (ROTEM), specifically evaluating for elevated clot strength or maximal amplitude (MA) suggestive of hypercoagulability (MA>80 $\mathrm{mm}$ ) [61•]. A D-dimer level above five times the upper limit of normal (ULN) has been suggested as an independent predictive factor that should be incorporated into risk assessment [57•, $61 \bullet, 63,64]$.

\section{Antiplatelet Therapy}

Aspirin is used as a thromboprophylaxis in MIS-C due to its role in addressing platelet activation, endothelial damage, and altered flow dynamics [57•, 65]. The use of aspirin was patterned after its use in Kawasaki disease, which appears to share fundamental characteristics with MIS-C, including altered flow dynamics in coronary vessels [33, 65-67].

Low-dose aspirin (3-5 mg/kg/day, maximum $81 \mathrm{mg} /$ day) should be considered in all hospitalized MIS-C patients, unless contraindicated (platelet count $<100,000 / \mathrm{mm}^{3}$, fibrinogen $<100 \mathrm{mg} / \mathrm{dL}$, active bleeding, or concern for high risk of bleeding) $[3 \bullet, 57 \bullet, 61 \bullet]$. Aspirin should be continued for at least 1 month from diagnosis regardless of inflammatory markers and coagulation profile or longer until levels normalize and coronary arteries are demonstrated to be normal $[5,66,67]$.

\section{Anticoagulant Thromboprophylaxis}

In addition to aspirin, the concomitant use of anticoagulation (e.g., low molecular weight heparin, unfractionated heparin (UFH), direct thrombin inhibitor, direct oral anticoagulant) in the absence of other bleeding risks (as exemplified in cases of significant risk of bleeding or platelet count $<20.000 / \mathrm{mm}^{3}$ ), is not contraindicated [57•, 64]. In noncritically ill adult patients hospitalized with COVID-19, therapeutic-dose anticoagulation was superior to usual-care thromboprophylaxis in increasing the probability of survival to discharge with reduced use of cardiovascular or respiratory organ support [68].

For MIS-C, recommendations for low-dose (prophylactic) anticoagulation include mild to moderate ventricular dysfunction, coronary dilation/aneurysm with z-score 2.5-10, D-dimer 5-10 $\times$ ULN, TEG MA $\geq 80 \mathrm{~mm}$, or any new significant rhythm abnormalities such as heart block, premature atrial and ventricular contractions, conduction abnormalities, and ST-segment changes [61 •]. The 2017 AHA recommendations for the management of Kawasaki disease can be used as guidelines for dosing regimens [65].

Consensus guidelines support the use of LMWH as the anticoagulant of choice for prophylactic dosing, which is commonly administered subcutaneously twice daily [69-71]. There is no consensus with regards to monitoring anti-Xa for prophylactic dosing, but one observational study suggests improved efficacy and safety with dosing titrated according to anti-Xa levels [63]. Unfractionated heparin, which has both hepatic and renal clearance and can be reversed with protamine sulfate, is an alternative if $\mathrm{LMWH}$ is contraindicated in cases of severe renal impairment. Heparininduced thrombocytopenia has been reported in COVID-19 patients and should be considered if a drop in platelet count is observed [57•, 65, 72]. 
Although not yet FDA approved for children, direct oral anticoagulants (DOACs) are increasingly used in patients with normal renal function and have no contraindications to their use. They can be considered for use as prophylactic anticoagulation $[57 \bullet, 61 \bullet]$.

Indications for initiating high-dose (treatment) anticoagulation include current or prior VTE, moderate-to-severe LV dysfunction $(\mathrm{EF}<35)$, giant coronary artery aneurysms (z-score $>10.0$ ), D-dimer $>10$ ULN, and laboratory changes consistent with myocardial ischemia $[3 \bullet, 57 \bullet, 61 \bullet]$. Patients can be switched to low-dose anticoagulation as echocardiogram and laboratory values improve.

For hospitalized patients with less severe MIS-C who do not have clear indications for anticoagulation, the approach to management should be individualized and tailored according to the patient's risk for thrombosis and risk of bleeding.

\section{Post-discharge Anticoagulation}

Consensus-based guidelines support the use of prophylacticdose anticoagulation for around 30 days post-discharge, with consideration of shorter or longer duration based on resolution or progression of clinical risk factors and laboratory values $[3 \bullet, 57 \bullet, 61 \bullet, 65]$.

Patients with MIS-C and documented thrombosis or $\mathrm{EF}>35 \%$ should receive therapeutic anticoagulation until at least 2 weeks after discharge from the hospital [3•]. Indications for longer outpatient therapeutic dosing include the following: CAAs with a z-score of $>10.0$ (indefinite treatment), documented thrombosis (treatment for $\geq 3$ months pending thrombus resolution), or ongoing moderate-to-severe LV dysfunction [3•]. For children with persistent risk factors, such as continued immobility, presence of central line, and significant D-dimer elevation, treatment should be continued until risk factors are no longer present $[3 \bullet, 57 \bullet]$.

\section{Other Therapies}

The use of extracorporeal membrane oxygenation (ECMO) varies considerably and should be considered in cases of ARDS or cardiorespiratory failure refractory to conventional management [57•, 73].

Therapeutic plasma exchange (TPE) is a well-known therapy designed to remove high molecular weight substances from the blood, with many non-specific mechanisms, including the removal of cytokines and autoantibodies. TPE is not routinely used in MIS-C, but has been used as a rescue immunomodulatory treatment in critically ill patients who have not responded to third-line immunomodulatory treatments or in cases in which biologic drugs are not available [74-77].

Remdesivir has not been well studied in the management of MIS-C and should not routinely be used; however, it can be considered for compassionate use on a case-by-case basis, particularly for those who are PCR positive [11, 57•].

\section{Limitations}

Limitations of current recommendations include reliance on observational studies and less applicability to low-resource settings in which access to complex diagnostic tools, IVIG, biologicals, and other therapies are more limited. The pharmacological approach that has been described here is also generally limited to those hospitalized with moderate-tosevere disease. Long-term outcomes of MIS-C patients remain unknown.

\section{Conclusions}

Here, we have reviewed the available literature on MIS-C therapies and presented treatment options, including the use of immunomodulators, thromboprophylactic agents, and other therapies. The timely and swift administration of immunomodulatory therapy improves outcomes and decreases the need for escalation of life-supportive care. In our review of data over time, we observed that patients treated according to later developed recommendations underpinned by prompt and aggressive immunomodulation, appeared to demonstrate lower mortality and lesser need for supportive care such as ECMO, compared to initial cohorts of patients who were treated with less aggressive immunomodulation.

Nevertheless, there remain significant knowledge deficits regarding the optimal selection of immunomodulatory therapies, especially with regards to long-term cardiac sequelae. A refined classification of the spectrum of different phenotypes and subtypes of illness related to MIS-C will likely allow for more precise determination of optimal therapies for specific, defined subgroups of patients.

Finally, the information and recommendations summarized in this article should not supersede the role of independent clinical judgment. Each patient will need an individualized, multidisciplinary approach in the context of his/ her clinical course.

Supplementary Information The online version contains supplementary material available at https://doi.org/10.1007/s40124-021-00259-4.

Acknowledgements The authors wish to thank Dr. Ashraf Harahsheh for reviewing their manuscript.

\section{Declarations}

Competing Interests The authors declare no competing interests. 
Open Access This article is licensed under a Creative Commons Attribution 4.0 International License, which permits use, sharing, adaptation, distribution and reproduction in any medium or format, as long as you give appropriate credit to the original author(s) and the source, provide a link to the Creative Commons licence, and indicate if changes were made. The images or other third party material in this article are included in the article's Creative Commons licence, unless indicated otherwise in a credit line to the material. If material is not included in the article's Creative Commons licence and your intended use is not permitted by statutory regulation or exceeds the permitted use, you will need to obtain permission directly from the copyright holder. To view a copy of this licence, visit http://creativecommons.org/licenses/by/4.0/.

\section{References}

Papers of particular interest, published recently, have been highlighted as: • Of importance

1. Dufort EM, Koumans EH, Chow EJ, Rosenthal EM, Muse A, Rowlands J, et al. Multisystem inflammatory syndrome in children in New York State. N Engl J Med. 2020;383:347-58. https://doi.org/10.1056/NEJMoa2021756.

2. Henderson LA, Canna SW, Friedman KG, Gorelik M, Lapidus SK, Bassiri H, et al. American College of Rheumatology Clinical Guidance for Multisystem Inflammatory Syndrome in Children Associated With SARS-CoV-2 and Hyperinflammation in Pediatric COVID-19: Version 1. Arthritis Rheumatol. 2020;72(11):1791-805. https://doi.org/10.1002/art.41454.

3. Henderson LA, Canna SW, Friedman KG, Gorelik M, Lapidus SK, Bassiri H, et al. American College of Rheumatology Clinical Guidance for Multisystem Inflammatory Syndrome in Children Associated With SARS-CoV-2 and Hyperinflammation in Pediatric COVID-19: Version 2. Arthritis Rheumatol. 2021;73(4):e13-29. https://doi.org/10.1002/art.41616. Comprehensive set of recommendations from the American College of Rheumatology, based on expert opinion and best available evidence as of November 2020.

4. Wu Z, McGoogan JM. Characteristics of and important lessons from the coronavirus disease 2019 (COVID-19) outbreak in China: summary of a report of 72314 cases from the Chinese Center for Disease Control and Prevention. JAMA. 2020;323(13):1239-42. https://doi.org/10.1001/jama.2020.2648.

5. Whittaker E, Bamford A, Kenny J, et al. PIMS-TS Study Group and EUCLIDS and PERFORM Consortia. Clinical characteristics of 58 children with a pediatric inflammatory multisystem syndrome temporally associated with SARS-CoV-2. JAMA. 2020;324(3):259-69. https://doi.org/10.1001/jama.2020.10369.

6. Toubiana J, Poirault C, Corsia A, Bajolle F, Fourgeaud J, Angoulvant F, et al. Kawasaki-like multisystem inflammatory syndrome in children during the covid-19 pandemic in Paris, France: prospective observational study. BMJ. 2020;369:m2094. https://doi.org/10.1136/bmj.m2094.

7. Feldstein LR, Rose EB, Horwitz SM, et al. Overcoming COVID19 Investigators; CDC COVID-19 Response Team. Multisystem inflammatory syndrome in US children and adolescents. N Engl J Med. 2020;383(4):334-46. https://doi.org/10.1056/NEJMo a2021680.

8. Jiang L, Tang K, Levin M, Irfan O, Morris SK, Wilson K, et al. COVID-19 and multisystem inflammatory syndrome in children and adolescents. Lancet Infect Dis. 2020;20(11):e276-88. https://doi.org/10.1016/S1473-3099(20)30651-4.

9. Pouletty M, Borocco C, Ouldali N, Caseris M, Basmaci R, Lachaume N, et al. Paediatric multisystem inflammatory syndrome temporally associated with SARS-CoV-2 mimicking Kawasaki disease (Kawa-COVID-19): a multicentre cohort. Ann Rheum Dis. 2020;79:999-1006.

10. Felsenstein S, Willis E, Lythgoe H, McCann L, Cleary A, Mahmood K, et al. Presentation, treatment response and shortterm outcomes in paediatric multisystem inflammatory syndrome temporally associated with SARS-CoV-2 (PIMS-TS). J Clin Med. 2020;9(10):E3293. https://doi.org/10.3390/jcm91 03293.

11. Matic KM. SARS-CoV-2 and multisystem inflammatory Syndrome in children (MIS-C). Curr Probl Pediatr Adolesc Health Care. 2021;51(4):101000. https://doi.org/10.1016/j.cppeds.2021. 101000.

12. Ramcharan T, Nolan O, Lai CY, Prabhu N, Krishnamurthy R, Richter AG, et al. Paediatric inflammatory multisystem syndrome: temporally associated with SARS-CoV-2 (PIMS-TS): cardiac features, management and short-term outcomes at a UK tertiary paediatric hospital. Pediatr Cardiol. 2020;41:1391401. https://doi.org/10.1007/s00246-020-02391-2.

13• Dove, M. L, Jaggi, P, Kelleman, M, Abuali, M, Ang, J. Y, Ballan, W, et al. (2021) Multisystem inflammatory syndrome in children: survey of protocols for early hospital evaluation and management. The Journal of pediatrics, 229;33-40. https://doi. org/10.1016/j.jpeds.2020.10.026. Detailed survey of protocols, with supplementary information including institutionally provided protocols.

14. Ouldali N, Toubiana J, Antona D, Javouhey E, Madhi F, Lorrot M, French Covid-19 Paediatric Inflammation Consortium, et al. Association of intravenous immunoglobulins plus methylprednisolone vs immunoglobulins alone with course of fever in multisystem inflammatory syndrome in children. JAMA. 2021;325(9):855-64. https://doi.org/10.1001/jama.2021.0694.

15. Nakra NA, Blumberg DA, Herrera-Guerra A, Lakshminrusimha S. Multi-system inflammatory syndrome in children (MIS-C) following SARS-CoV-2 infection: review of clinical presentation, hypothetical pathogenesis, and proposed management. Children (Basel). 2020;7(7):69. https://doi.org/10.3390/child ren7070069.

16. Ouldali N, Pouletty M, Mariani P, Beyler C, Blachier A, Bonacorsi S, et al. Emergence of Kawasaki disease related to SARSCoV-2 infection in an epicentre of the French COVID-19 epidemic: a time-series analysis. Lancet Child Adolesc Health. 2020;4(9):662-8. https://doi.org/10.1016/S2352-4642(20) 30175-9.

17. Cheng MH, Zhang S, Porritt RA, Noval Rivas M, Paschold L, Willscher E, et al. Superantigenic character of an insert unique to SARS-CoV-2 spike supported by skewed TCR repertoire in patients with hyperinflammation. Proc Natl Acad Sci USA. 2020;117(41):25254-62. https://doi.org/10.1073/pnas.20107 22117.

18. Rivas MN, Porritt RA, Cheng MH, Bahar I, Arditi M. COVID19 -associated multisystem inflammatory syndrome in children (MIS-C): a novel disease that mimics toxic shock syndrome-the superantigen hypothesis. J Allergy Clin Immunol. 2021;147(1):57-9. https://doi.org/10.1016/j.jaci.2020.10.008.

19. Kabeerdoss J, Pilania RK, Karkhele R, Kumar TS, Danda D, Singh S. Severe COVID-19, multisystem inflammatory syndrome in children, and Kawasaki disease: immunological mechanisms, clinical manifestations and management. Rheumatol Int. 2021;41(1):4119-32. https://doi.org/10.1007/ s00296-020-04749-4.

20. Harwood R, Allin B, Jones CE, Whittaker E, Ramnarayan P, Ramanan AV, PIMS-TS National Consensus Management Study Group, et al. A national consensus management pathway for paediatric inflammatory multisystem syndrome temporally associated with COVID-19 (PIMS-TS): results of a national 
Delphi process. Lancet Child Adolesc Health. 2021;5(2):13341. https://doi.org/10.1016/S2352-4642(20)30304-7.

21. Viner RM, Whittaker E. Kawasaki-like disease: emerging complication during the COVID-19 pandemic. Lancet. 2020;395(10239):1741-3. https://doi.org/10.1016/S01406736(20)31129-6.

22 Son MBF, Murray N, Friedman K, Young CC, Newhams MM, Feldstein LR, Overcoming COVID-19 Investigators, et al. Multisystem Inflammatory Syndrome in Children. Initial Therapy and Outcomes. N Engl J Med. 2021;385(1):23-34. https://doi. org/10.1056/NEJMoa2102605.

23. Ballow MJ. The IgG molecule as a biological immune response modifier: mechanisms of action of intravenous immune serum globulin in autoimmune and inflammatory disorders. Allergy Clin Immunol. 2011;127(2):315-23. https://doi.org/10.1016/j. jaci.2010.10.030.

24. Belhadjer Z, Meot M, Bajolle F, Khraiche D, Legendre A, Abakka S, et al. Acute heart failure in multisystem inflammatory syndrome in children (MIS-C) in the context of global SARSCoV-2 pandemic. Circulation. 2020;142(5):429-36. https://doi. org/10.1161/CIRCULATIONAHA.120.048360.

25 Jone PN, Everitt MD. Management of multisystem inflammatory syndrome in children associated with COVID-19 infection. Curr Treat Options Peds. 2021;7:1-10. https://doi.org/10.1007/ s40746-021-00224-9.

26. Merckx J, Cooke S, El Tal T, Laxer RM, Bitnun A, Morris SK, et al. Multicenter cohort study of multisystem inflammatory syndrome in children (MIS-C). medRxiv. 2021.05.14.21257058; https://doi.org/10.1101/2021.05.14.21257058

27. Harahsheh AS, Krishnan A, DeBiasi RL, Olivieri LJ, Spurney C, Donofrio MT, et al. Cardiac echocardiogram findings of severe acute respiratory syndrome coronavirus-2-associated multisystem inflammatory syndrome in children. Cardiol Young. 2021;2021:1-9. https://doi.org/10.1017/S1047951121003024.

28. Schlapbach LJ, Andre MC, Grazioli S, Schöbi N, Ritz N, Aebi C, PIMS-TS working group of the Interest Group for Pediatric Neonatal Intensive Care (IGPNI) of the Swiss Society of Intensive Care and the Pediatric Infectious Diseases Group Switzerland (PIGS), et al. Best practice recommendations for the diagnosis and management of children with pediatric inflammatory multisystem syndrome temporally associated with SARS-CoV-2 (PIMS-TS; multisystem inflammatory syndrome in children, MIS-C) in Switzerland. Front Pediatr. 2021;9:667507. https:// doi.org/10.3389/fped.2021.667507. Comprehensive set of recommendations based on $>\mathbf{8 0} \%$ of agreement from 24 panelists from the Interest Group for Pediatric and Neonatal Intensive Care (IGPNI) of the Swiss Society of Intensive Care Medicine (SSICM) and the Pediatric Infectious Diseases Group Switzerland (PIGS).

29. Horby P, Lim WS, Emberson JR, Mafham M, Bell JL, Linsell L, RECOVERY Collaborative Group, et al. Dexamethasone in hospitalized patients with Covid-19. N Engl J Med. 2021;384(8):693-704. https://doi.org/10.1056/NEJMoa2021 436.

30 Sterne JAC, Murthy S, Diaz JV, et al. WHO rapid evidence appraisal for COVID-19 Therapies (REACT) Working Group. Association between administration of systemic corticosteroids and mortality among critically ill patients with COVID-19: meta-analysis. JAMA. 2020;324(13):1330-41. https://doi.org/ 10.1001/jama.2020.17023.

31 Elias MD, McCrindle BW, Larios G, Choueiter NF, Dahdah N, of the International Kawasaki Disease Registry, et al. Management of multisystem inflammatory syndrome in children associated with COVID-19: a survey from the International Kawasaki Disease Registry. CJC Open. 2020;2(6):632-40. https://doi.org/ 10.1016/j.cjco.2020.09.004
32. Belhadjer Z, Auriau J, Méot M, Oualha M, Renolleau S, Houyel $\mathrm{L}$, et al. Addition of corticosteroids to immunoglobulins is associated with recovery of cardiac function in multi-inflammatory syndrome in children. Circulation. 2020;142(23):2282-4. https:// doi.org/10.1161/CIRCULATIONAHA.120.050147. Observational study suggesting efficacy to combination therapy with corticosteroids and IVIG.

33 McArdle AJ, Vito O, Patel H, Seaby EG, Shah P, Wilson C, et al. BATS Consortium. Treatment of multisystem inflammatory syndrome in children. N Engl J Med. 2021;385(1):11-22. https://doi.org/10.1056/NEJMoa2102968.

34 DeBiasi RL. Immunotherapy for MIS-C. IVIG, glucocorticoids, and biologics. N Engl J Med. 2021;385(1):74-5. https://doi.org/ 10.1056/NEJMe2108276.

35. Ranjbar K, Moghadami M, Mirahmadizadeh A, Fallahi MJ, Khaloo V, Shahriarirad R, et al. Methylprednisolone or dexamethasone, which one is superior corticosteroid in the treatment of hospitalized COVID-19 patients: a triple-blinded randomized controlled trial. BMC Infect Dis. 2021;21(1):337. https://doi.org/10.1186/s12879-021-06045-3.

36. Esposito S, Principi N. Multisystem inflammatory syndrome in children related to SARS-CoV-2. Paediatr Drugs. 2021;23(2):119-29. https://doi.org/10.1007/ s40272-020-00435-x.

37. Waltuch T, Gill P, Zinns LE, Whitney R, Tokarski J, Tsung JW, et al. Features of COVID-19 post-infectious cytokine release syndrome in children presenting to the emergency department. Am J Emerg Med. 2020;38(10):2246.e3-2246.e6. https://doi. org/10.1016/j.ajem.2020.05.058.

38. Schett G, Manger B, Simon D, Caporali R. COVID-19 revisiting inflammatory pathways of arthritis. Nat Rev Rheumatol. 2020;16(8):465-70. https://doi.org/10.1038/ s41584-020-0451-z.

39. Yoshikawa T, Hill T, Li K, Peters CJ, Tseng CT. Severe acute respiratory syndrome (SARS) coronavirus-induced lung epithelial cytokines exacerbate SARS pathogenesis by modulating intrinsic functions of monocyte-derived macrophages and dendritic cells. J Virol. 2009;83(7):3039-48. https://doi.org/10. 1128/JVI.01792-08.

40 Cavalli G, Dinarello CA. Anakinra therapy for non-cancer inflammatory diseases. Front Pharmacol. 2018;9:1157. https:// doi.org/10.3389/fphar.2018.01157.

41. Balkhair A, Al-Zakwani I, Al Busaidi M, Al-Khirbash A, Al Mubaihsi S, BaTaher H, et al. Anakinra in hospitalized patients with severe COVID-19 pneumonia requiring oxygen therapy: results of a prospective, open-label, interventional study. Int $\mathbf{J}$ Infect Dis. 2021;103:288-96. https://doi.org/10.1016/j.ijid.2020. 11.149.

42. Cavalli G, De Luca G, Campochiaro C, Della-Torre E, Ripa M, Canetti D, et al. Interleukin-1 blockade with high-dose anakinra in patients with COVID-19, acute respiratory distress syndrome, and hyperinflammation: a retrospective cohort study. Lancet Rheumatol. 2020;2(6):e325-31. https://doi.org/10.1016/S26659913(20)30127-2.

43. Cauchois R, Koubi M, Delarbre D, Manet C, Carvelli J, Blasco VB, et al. Early IL-1 receptor blockade in severe inflammatory respiratory failure complicating COVID-19. Proc Natl Acad Sci U S A. 2020;117(32):18951-3. https://doi.org/10.1073/pnas. 2009017117.

44. Huet T, Beaussier H, Voisin O, Jouveshomme S, Dauriat G, Lazareth I, et al. Anakinra for severe forms of COVID-19: a cohort study. Lancet Rheumatol. 2020;2(7):e393-400. https:// doi.org/10.1016/S2665-9913(20)30164-8.

45. Bozzi G, Mangioni D, Minoia F, Aliberti S, Grasselli G, Barbetta L, et al. Anakinra combined with methylprednisolone in patients with severe COVID-19 pneumonia and 
hyperinflammation: an observational cohort study. J Allergy Clin Immunol. 2021;147(2):561-566.e4. https://doi.org/10.1016/j. jaci.2020.11.006.

46. Della Paolera S, Valencic E, Piscianz E, Moressa V, Tommasini A, Sagredini R, et al. Case Report: Use of anakinra in multisystem inflammatory syndrome during COVID-19 pandemic. Front Pediatr. 2021;8:624248. https://doi.org/10.3389/fped.2020. 624248.

47. Hennon TR, Penque MD, Abdul-Aziz R, Alibrahim OS, McGreevy MB, Prout AJ, et al. COVID-19 associated multisystem inflammatory syndrome in children (MIS-C) guidelines; a Western New York approach. Prog Pediatr Cardiol. 2020;2020:101232. https://doi.org/10.1016/j.ppedcard.2020. 101232.

48. Xu X, Han M, Li T, Sun W, Wang D, Fu B, et al. Effective treatment of severe COVID-19 patients with tocilizumab. Proc Natl Acad Sci U S A. 2020;117(20):10970-5. https://doi.org/10.1073/ pnas.2005615117.

49. Capra R, De Rossi N, Mattioli F, Romanelli G, Scarpazza C, Sormani MP, et al. Impact of low dose tocilizumab on mortality rate in patients with COVID-19 related pneumonia. Eur J Intern Med. 2020;76:31-5. https://doi.org/10.1016/j.ejim.2020.05.009.

50 Stone JH, Frigault MJ, Serling-Boyd NJ, Fernandes AD, Harvey L, Foulkes AS, et al. BACC Bay Tocilizumab Trial Investigators. Efficacy of tocilizumab in patients hospitalized with Covid-19. N Engl J Med. 2020;383(24):2333-44. https://doi.org/10.1056/ NEJMoa2028836.

51. Hermine O, Mariette X, Tharaux PL, Resche-Rigon M, Porcher R, Ravaud P, CORIMUNO-19 Collaborative Group. Effect of tocilizumab vs usual care in adults hospitalized with COVID-19 and moderate or severe pneumonia: a randomized clinical trial. JAMA Intern Med. 2021;181(1):32-40. https://doi.org/10.1001/ jamainternmed.2020.6820.

52. Diorio C, Henrickson SE, Vella LA, McNerney KO, Chase J, Burudpakdee $\mathrm{C}$, et al. Multisystem inflammatory syndrome in children and COVID-19 are distinct presentations of SARSCoV-2. J Clin Invest. 2020;130(11):5967-75. https://doi.org/ 10.1172/JCI140970.

53. Abdel-Haq N, Asmar BI, Deza Leon MP, McGrath EJ, Arora HS, Cashen K, et al. SARS-CoV-2-associated multisystem inflammatory syndrome in children: clinical manifestations and the role of infliximab treatment. Eur J Pediatr. 2021;180(5):1581-91. https://doi.org/10.1007/s00431-021-03935-1.

54. Dolinger MT, Person H, Smith R, Jarchin L, Pittman N, Dubinsky MC, et al. Pediatric Crohn disease and multisystem inflammatory syndrome in children (MIS-C) and COVID-19 treated with infliximab. J Pediatr Gastroenterol Nutr. 2020;71(2):153-5. https://doi.org/10.1097/MPG.0000000000002809.

55. Branchford BR, Mahajerin A, Raffini L, Chalmers E, van Ommen CH, Chan AKC, Goldenberg NA, Subcommittee on Pediatric/Neonatal Hemostasis and Thrombosis. Recommendations for standardized risk factor definitions in pediatric hospitalacquired venous thromboembolism to inform future prevention trials: communication from the SSC of the ISTH. J Thromb Haemost. 2017;15(11):2274-8. https://doi.org/10.1111/jth.13848.

56. Iba T, Connors JM, Levy JH. The coagulopathy, endotheliopathy, and vasculitis of COVID-19. Inflamm Res. 2020;69(12):1181-9. https://doi.org/10.1007/s00011-020-01401-6.

57. Sharathkumar AA, Faustino EVS, Takemoto CM. How we approach thrombosis risk in children with COVID-19 infection and MIS-C. Pediatr Blood Cancer. 2021;68(7):e29049. https:// doi.org/10.1002/pbc.29049. Comprehensive article using clinical vignettes to illustrate approaches to assessing thrombosis and decision making regarding thromboprophylaxis.
58. Nicolai L, Leunig A, Brambs S, Kaiser R, Weinberger T, Weigand $\mathrm{M}$, et al. Immunothrombotic dysregulation in COVID-19 pneumonia is associated with respiratory failure and coagulopathy. Circulation. 2020;142(12):1176-89. https://doi.org/10.1161/ CIRCULATIONAHA.120.048488.

59 Fernandes DM, Oliveira CR, Guerguis S, Eisenberg R, Choi J, Kim M, et al. Tri-State Pediatric COVID-19 Research Consortium. Severe acute respiratory syndrome coronavirus 2 clinical syndromes and predictors of disease severity in hospitalized children and youth. J Pediatr. 2021;230:23-31.e10. https://doi. org/10.1016/j.jpeds.2020.11.016.

60. Whitworth H, Sartain SE, Kumar R, Armstrong K, Ballester $\mathrm{L}$, Betensky M, et al. Rate of thrombosis in children and adolescents hospitalized with COVID-19 or MIS-C. Blood. 2021;138(2):190-8. https://doi.org/10.1182/blood.2020010218.

61.• Bansal N, Azeka E, Neunert C, Kim JS, Murray J, May L, et al. Multisystem inflammatory syndrome associated with COVID-19 anti-thrombosis guideline of care for children by action. Pediatr Cardiol. 2021:1-5. https://doi.org/10.1007/s00246-021-026519. Concise set of consensus recommendations from the Advanced Cardiac Therapies Improving Outcomes Network (ACTION).

62 Shekerdemian LS, Mahmood NR, Wolfe KK, Riggs BJ, Ross CE, McKiernan CA, et al. International COVID-19 PICU Collaborative. Characteristics and outcomes of children with coronavirus disease 2019 (COVID-19) infection admitted to US and Canadian Pediatric Intensive Care Units. JAMA Pediatr. 2020;174(9):868-73. https://doi.org/10.1001/jamapediatrics. 2020.1948

63 Mitchell WB, Davila J, Keenan J, Jackson J, Tal A, Morrone $\mathrm{KA}$, et al. Children and young adults hospitalized for severe COVID-19 exhibit thrombotic coagulopathy. Pediatr Blood Cancer. 2021;68(7):e28975. https://doi.org/10.1002/pbc.28975.

64. Goldenberg NA, Sochet A, Albisetti M, Biss T, Bonduel M, Jaffray J, et al. Pediatric/Neonatal Hemostasis and Thrombosis Subcommittee of the ISTH SSC. Consensus-based clinical recommendations and research priorities for anticoagulant thromboprophylaxis in children hospitalized for COVID-19-related illness. J Thromb Haemost. 2020;18(11):3099-105. https://doi. org/10.1111/jth.15073.

65. McCrindle BW, Rowley AH, Newburger JW, Burns JC, Bolger AF, Gewitz M, et al. American Heart Association Rheumatic Fever, Endocarditis, and Kawasaki Disease Committee of the Council on Cardiovascular Disease in the Young; Council on Cardiovascular and Stroke Nursing; Council on Cardiovascular Surgery and Anesthesia; and Council on Epidemiology and Prevention. Diagnosis, Treatment, and Long-Term Management of Kawasaki Disease: A Scientific Statement for Health Professionals From the American Heart Association. Circulation. 2017;135(17):e927-99. https://doi.org/10.1161/CIR.00000 00000000484.

66. Consiglio CR, Cotugno N, Sardh F, Pou C, Amodio D, Rodriguez L, et al. The immunology of multisystem inflammatory syndrome in children with COVID-19. Cell. 2020;183(4):968981.e7. https://doi.org/10.1016/j.cell.2020.09.016.

67 Rowley AH. Understanding SARS-CoV-2-related multisystem inflammatory syndrome in children. Nat Rev Immunol. 2020;20(8):453-4. https://doi.org/10.1038/s41577-020-0367-5.

68 Lawler PR, Goligher EC, Berger JS, Neal MD, McVerry BJ, Nicolau JC, et al. ATTACC Investigators; ACTIV-4a Investigators; REMAP-CAP Investigators. Therapeutic Anticoagulation with Heparin in Noncritically Ill Patients with Covid-19. N Engl J Med. 2021;2021:NEJMoa2105911. https://doi.org/10.1056/ NEJMoa2105911. 
69. Monagle P, Chan AKC, Goldenberg NA, Ichord RN, Journeycake JM, Nowak-Göttl U, et al. Antithrombotic therapy in neonates and children: antithrombotic therapy and prevention of Thrombosis, 9th ed: American College of Chest Physicians Evidence-Based Clinical Practice Guidelines. Chest. 2012;141(2 Suppl):e737S-e801S. https://doi.org/10.1378/chest.11-2308.

70 Malowany JI, Monagle P, Knoppert DC, Lee DS, Wu J, McCusker P, et al. Canadian Paediatric Thrombosis and Hemostasis Network. Enoxaparin for neonatal thrombosis: a call for a higher dose for neonates. Thromb Res. 2008;122(6):826-30. https://doi.org/10.1016/j.thromres.2007.11.009.

71. Richard AA, Kim S, Moffett BS, Bomgaars L, Mahoney D Jr, Yee DL. Comparison of anti-Xa levels in obese and non-obese pediatric patients receiving treatment doses of enoxaparin. $\mathbf{J}$ Pediatr. 2013;162(2):293-6. https://doi.org/10.1016/j.jpeds. 2012.07.047.

72. Warkentin TE. Challenges in Detecting Clinically Relevant Heparin-Induced Thrombocytopenia Antibodies. Hamostaseologie. 2020;40(4):472-84. https://doi.org/10.1055/a-1223-3329.

73. Kache S, Chisti MJ, Gumbo F, Mupere E, Zhi X, Nallasamy K, et al. COVID-19 PICU guidelines: for high- and limitedresource settings. Pediatr Res. 2020;88(5):705-16. https://doi. org/10.1038/s41390-020-1053-9.

74. Keith P, Day M, Perkins L, Moyer L, Hewitt K, Wells A. A novel treatment approach to the novel coronavirus: an argument for the use of therapeutic plasma exchange for fulminant COVID-19. Crit Care. 2020;24(1):128. https://doi.org/10.1186/ s13054-020-2836-4.

75. Luo S, Yang L, Wang C, Liu C, Li D. Clinical observation of 6 severe COVID-19 patients treated with plasma exchange or tocilizumab]. Zhejiang Da Xue Xue Bao Yi Xue Ban. 2020;49(2):227-231. Chinese. https://doi.org/10.3785/j.issn. 1008-9292.2020.03.06.

76. Díaz F, Cores C, Atenas O, Rodríguez N, Bustos R, Cruces P. Rationale of therapeutic plasma exchange as rescue immunomodulatory treatment for MIS-C with multiorgan failure. Pediatr Infect Dis J. 2021;40(7):e259-62. https://doi.org/10. 1097/INF.0000000000003169.

77. Emeksiz S, Özcan S, Perk O, Uyar E, Çelikel Acar B, Kibar Gül AE, et al. Therapeutic plasma exchange: a potential management strategy for critically ill MIS-C patients in the pediatric intensive care unit. Transfus Apher Sci. 2021;2021:103119. https://doi. org/10.1016/j.transci.2021.103119.

Publisher's Note Springer Nature remains neutral with regard to jurisdictional claims in published maps and institutional affiliations. 